\title{
MicroRNA as Biomarker for Breast Cancer Detection
}

N.F.Al-Hussein ${ }^{1}$, N.M.Emarah ${ }^{2}$, Y.M.Marei ${ }^{1}{ }^{\text {H.E.Nasr }}{ }^{1}$ and R.S.Mohamed $^{1}$

${ }^{1}$ Medical Biochemistry \& Molecular Biology, Dept., Faculty of Medicine, Benha Univ., Benha, Egypt

${ }^{2}$ Pathology, Dept., Faculty of Medicine, Benha Univ., Benha, Egypt

E-mail:reemsafwat99@gmail.com

\begin{abstract}
Women are more likely than men to die from cancer if they have breast cancer (BC). It was triggered by a slew of risk factors. Breast cancer patients have a better prognosis if they are diagnosed early. Recent research has shown that microRNAs may play an important role in the early detection and prognosis of breast cancer. There are approximately 23 nucleotides in microRNAs, making them tiny uncoding RNAs. Breast cancer development may be slowed or halted through the control of cell proliferation and death by miRNAs. MicroRNA-329 (miRNA-329) expression was examined in BC females to see whether it was associated with the disease's stage and to determine if miRNA-329 might be used in the diagnosis of BC.
\end{abstract}

Keywords: Breast Cancer, MiRNAs.

\section{Introduction}

Breast cancer is the top cause of cancer mortality in women across the globe, and is one of the most often diagnosed malignancies. An estimated 246,660 female patients in the United States will be diagnosed with $\mathrm{BC}$ by the end of the year, with a death toll of 40,450. [1]. However, despite advances in cancer screening methods, significant difficulties still exist in improving management options for this illness [2].

$\mathrm{BC}$ is projected to be the most prevalent cancer among Egyptian women, accounting for $38.8 \%$ of all cancer diagnoses and $29.1 \%$ of all cancer-related fatalities [3].

Early detection of $\mathrm{BC}$ may be achieved via a variety of methods, including self-examination of the breast and mammography screening. Although all current techniques have some degree of accuracy, mammography is especially challenging to interpret in younger women owing to dense breast tissue. Recent years have seen considerable research towards the development of early-stage blood-based biomarkers to assist imaging techniques for the identification of $\mathrm{BC}$ [4]. Gene expression, proteins, and miRNA expression profiles are examples of possible molecular marker possibilities [4]. Consequently, developing a new biomarker-based test for the early detection of breast cancer that has high sensitivity and specificity is a top priority.

They are approximately 23 nucleotides in length and are non-coding RNAs. Gene silence is initiated by degrading mRNA targets, and this controls the activities of many genes. In the past several years, a large body of data has gathered indicating that microRNAs play an important role in the development of many illnesses [5]. Researchers believe that abnormalities in miRNA expression levels have a role in cancer development and progression [6].

Many studies have shown that miRNAs are dysregulated in all phases of $\mathrm{BC}$, suggesting that they may serve as diagnostic and prognostic indicators [7].

$14 q 32.31$ is home to MiR-329 [8]. Because of its abnormal expression in some kinds of cancer tissues, MiR-329 is suspected of acting as a tumour suppressor in many malignancies [9].
These researchers want to learn more about the pattern of miRNA-329 expression in breast cancer patients and whether or not they can utilise it as a diagnostic or predictive sign for the disease.

\section{Subject and methods}

Benha Faculty of Medicine's research ethics council approved the study plan, and the participants gave their informed permission before the research could begin in December 2020. The results were collected between May 2021 and October 2022. This research comprised 40 female participants who were recruited from the Benha University Hospital's Department of General Surgery, Faculty of Medicine. The BC group included 25 female patients, whereas the control group had a 15 number of females, all of whom were in good health.

Extraction of miRNA from tissue samples: following the manufacturer's instructions using the PureLink ${ }^{\circledR}$ RNA Mini Kit (Ambion, USA). For the synthesis of cDNA, we used Thermo Scientific's RevertAid First Strand cDNA Synthesis Kit (following the manufacturer's instructions). According to manufacturer's instructions, use of Maxima SYBR Green qPCR Master Mix (2X; Thermo Scientific, United States) for detection of miR-329 was carried out using qRT-PCR.

\subsection{Statistical analysis}

In terms of quantitative data, the gathered information was described as mean + Standard Deviation (SD) and range, and in terms of qualitative data, as frequency and percentage. In order to compare quantitative data between two groups, we used the student-T test, and in order to compare proportions between two or more groups, we used the Chi-squared test (2). The association between miRNA-329 and the study subjects' ages was estimated using Pearson correlation. appropriate P-values were computed by using test statistics and test statistics. As long as Pvalue was less than or equal to 0.05 , it was deemed statistically significant. For data processing and analysis, the Statistics Program for Social Sciences (SPSS) is utilised, along with Microsoft Office Excel 


\section{Results}

The baseline characteristics of the study population are presented in Table-1. There was insignificant difference between cases and control groups regarding age $\&$ age at menarche.

microRNA 329, were studied and their expression was analyzed in tissue samples. The expression of miR-329 was significantly lower $(\mathrm{p}<0.001)$ in breast cancer tissues as compared to controls (table 2 ).

Table (1) Demographic data of the studied groups

\begin{tabular}{lllll}
\hline & & Cases group & Control group & p- value \\
\hline Age & mean \pm SD & $45 \pm 9.59$ & $47.0 \pm 12.14$ & 0.39 \\
Age at menarche & mean \pm SD & $12.5 \pm 1.43$ & $12.43 \pm 1.72$ & 0.87 \\
\hline
\end{tabular}

Expression level of miRNA 329 of studied groups

Table (2) Difference between breast cancer group and control group regarding miR 329 relative expression.

\begin{tabular}{|c|c|c|c|c|}
\hline $\begin{array}{l}\text { Study Group } \\
\text { MiR-329 (Log) } \\
\end{array}$ & Control group & $\begin{array}{c}\text { breast cancer } \\
\text { group } \\
\end{array}$ & T- Test & P-value \\
\hline $\begin{array}{l}\text { Mean } \\
\pm \text { SD }\end{array}$ & $\begin{array}{c}780567.4 \\
\pm 7528 \\
\end{array}$ & $\begin{array}{c}385835 \\
\pm 170425 \\
\end{array}$ & 10.915 & $<0.001$ \\
\hline
\end{tabular}

SD: Standard deviation, P $0.05 \leq$ significant, $\mathrm{P}>0.05$ non-significant, analysis done by independent samples Student T test.

\section{Discussion}

Breast cancer $(\mathrm{BC})$ is a malignant illness that affects a large percentage of women worldwide. British Columbia has the highest mortality rate for women in the world in 2012, with 522,000 fatalities [11]. There are many distant organs that may be affected by metastatic breast cancer, which is why it's so difficult to treat after it has spread. It is possible that early detection of the illness will result in a favourable prognosis and a high survival rate [12]. Mammography is a screening method for breast cancer that has shown to be successful in lowering death rates [12]. There are many treatment options available for women who have been diagnosed with a breast tumour. These include targeted therapy, hormone therapy, radiation therapy, surgery, and chemotherapy, among others [13].

MiRNAs regulate the expression of immigration and angiogenesis-related genes as tumour suppressors or oncogenes [14]. Because of the role miRNAs play in gene regulation and the fact that they've been linked to a variety of illnesses, including cancer, their use in clinical diagnosis, prognosis, and therapy is becoming popular [15].

A large number of miRNAs have been shown to be substantially dysregulated in breast cancer and have either suppressive or oncogenic functions [16]. In renal cell carcinoma tissues, for example, tumour suppressor microRNA-205 was shown to be active and to slow the growth of tumour cells [17]. Tumor cell invasion and migration were shown to be associated with MicroRNA-584 in thyroid cancer [18].

A miRNA known as MiR-329 has been widely researched in the context of cancer, and prior studies have shown the therapeutic use of this miRNA [19].

By using qRT-PCR, the authors were able to determine the expression levels of miR-329. Breast cancer women had lower levels of miR-329 expression in their blood than healthy women did, according to our research. These findings suggest that miR-329 may serve as a tumour suppressor in women with breast cancer.

\section{References}

[1] R. L.Siegel, K. D.Miller, A.Jemal. Cancer statistics, 2016. CA: a cancer journal for clinicians. Vol. 66(1), pp. 7-30, 2016.

[2] A.Jemal, F.Bray, M. M.Center, J.Ferlay, E.Ward, D.Forman. Global cancer statistics. CA: a cancer journal for clinicians. Vol.61(2), pp. 69-90, 2011.

[3] A. S.Ibrahim, H. M.Khaled, N. N.Mikhail, H.Baraka , H.Kamel. Cancer incidence in Egypt: results of the national populationbased cancer registry program. Journal of cancer epidemiology. Vol. 4, pp.569 , 2014.

[4] M.Kahraman, A.Röske, T.Laufer, T.Fehlmann, C.Backes, F.Kern, M. G. Schrauder. MicroRNA in diagnosis and therapy monitoring of early-stage triplenegative breast cancer. Scientific reports. Vol. 8(1),pp. 1-11, 2018.

[5] G. D.Femminella, N.Ferrara, G.Rengo. The emerging role of microRNAs in Alzheimer's disease. Frontiers in physiology. Vol.6, pp. 40, 2015.

[6] E. I.Palmero, S. G. P.de Campos, M.Campos, N. C.Souza, I. D. C.Guerreiro, A. L.Carvalho, M. M. C. Marques. Mechanisms and role of microRNA deregulation in cancer onset and progression. Genetics and molecular biology. Vol. 34, pp. 363-370, 2011. 
[7] J.Inns, V.James. Circulating microRNAs for the prediction of metastasis in breast cancer patients diagnosed with early stage disease. The Breast. Vol.24(4), pp. 364-369, 2015.

[8] H. Q.Liang, R. J.Wang, C. F.Diao, J. W.Li, J. L.Su, S.Zhang. The PTTG1-targeting miRNAs miR-329, miR-300, miR-381, and miR-655 inhibit pituitary tumor cell tumorigenesis and are involved in a p53/PTTG1 regulation feedback loop. Oncotarget. Vol. 6(30), pp. 294, 2015.

[9] W.Jiang, J.Liu, T.Xu, X.Yu. MiR-329 suppresses osteosarcoma development by downregulating Rab10. FEBS letters. Vol. 590(17), pp. 2973-2981, 2016.

[10]E.Said, A.Zidan, A.Nawar, N.Alhusseini, E.Soliman, R.Shaker, H.Baiumy. Circulating Micro RNA-21 and-92a as Biomarkers of Colorectal Cancer. Afro-Egyptian Journal of Infectious and Endemic Diseases. Vol. 7(4), pp.247-257, 2017.

[11]F.Bray, J. S.Ren, E.Masuyer, J.Ferlay. Global estimates of cancer prevalence for 27 sites in the adult population in 2008 . International journal of cancer. Vol. 132(5), pp.1133-1145, 2013.

[12] Y. S.Sun, Z.Zhao, Z. N.Yang, F.Xu, H. J.Lu, Z. Y.Zhu, H. P. Zhu. Risk factors and preventions of breast cancer. International journal of biological sciences. Vol. 13(11),pp. 1387, 2017.

[13] M.Akram, M.Iqbal, M.Daniyal, A. U. Khan. Awareness and current knowledge of breast cancer. Biological research. Vol. 50(1), pp. 1-23, 2017.

[14] X. R.Tang, X.Wen, Q. M.He, Y. Q.Li, X. Y.Ren, X. J.Yang, N.Liu. MicroRNA-101 inhibits invasion and angiogenesis through targeting ITGA3 and its systemic delivery inhibits lung metastasis in nasopharyngeal carcinoma. Cell death \& disease. Vol. 8(1), pp.e2566-e2566, 2018.

[15]D. A.Armstrong, A. B.Nymon, C. S.Ringelberg, C.Lesseur, H. F.Hazlett, L.Howard, A.Ashare. Pulmonary microRNA profiling: implications in upper lobe predominant lung disease. Clinical epigenetics. Vol. 9(1),pp. 1-9, 2017.

[16] Y.Ji, Z.Han, L.Shao, Y.Zhao. Evaluation of in vivo antitumor effects of lowfrequency ultrasound-mediated miRNA-133a microbubble delivery in breast cancer. Cancer medicine. Vol. 5(9), pp.2534-2543, 2016.

[17]Z.Chen, Z. Y.Tang, Y.He, L. F.Liu, D. J.Li, X.Chen. miRNA-205 is a candidate tumor suppressor that targets ZEB2 in renal cell carcinoma. Oncology research and treatment. Vol. 37(11), pp. 658-664, 2014.

[18] J.Xiang, Y.Wu, D. S.Li, Z. Y.Wang, Q.Shen, T. Q.Sun, Y. J.Wang. miR-584 suppresses invasion and cell migration of thyroid carcinoma by regulating the target oncogene ROCK1. Oncology research and treatment. Vol. 38(9), pp.436-440, 2015.

[19]C. C.Sun, S. J.Li, F.Zhang, J. Y.Pan, L.Wang, C. L.Yang, D. J.Li. Hsa-miR-329 exerts tumor suppressor function through down-regulation of MET in non-small cell lung cancer. Oncotarget. Vol. 7(16), pp. 21510,2016 . 